\title{
Measurements and calculations of capacitances of BJT and SJT made of silicon carbide
}

\author{
Joanna Szelągowska ${ }^{1, *}$ and Janusz Zarębski ${ }^{1}$ \\ ${ }^{1}$ Gdynia Maritime University, Dept. of Marine Electronics, Morska 83, 81-225 Gdynia, Poland
}

\begin{abstract}
In the paper the results of capacitance-voltage $(\mathrm{C}-\mathrm{V})$ characteristics measurements of the current controlled BJT and SJT transistors were presented, for which a programmable measuring system manufactured by Keithley was used. The results of measurements was compared with results of the calculations obtained by using the commonly used Gummel-Poon model. For comparison, the results of the measurements found in the literature and in the datasheets of the considered devices were presented as well. The temperature impact on the shape of the considered characteristics was also investigated.
\end{abstract}

\section{Introduction}

The rapid development of electronic technology makes silicon carbide $(\mathrm{SiC})$ one of the most promising materials for producing high power semiconductor devices with relatively short switching times $[1,2]$. This group of devices includes current controlled transistors such as classic SiC BJT (Bipolar Junction Transistors) offered by TranSiC [3] and modern SJT (Silicon Carbide Junction Transistor) with a relatively high current gain factor, offered since 2011 by GeneSiC [4]. The paper presents the form of the Gummel-Poon model and an evaluation of the accuracy of this model in determining the capacitance-voltage characteristics of arbitrarily selected BJT and SJT made of silicon carbide. The results of the calculations were compared with the results of the measurements. The temperature impact on the shape of considered characteristics was also investigated.

\section{Gummel-Poon model form}

In practice, modelling characteristics of a current controlled transistors is most often realised by using the Gummel-Poon model $[5,6]$. The popularity of this model is evidenced by the fact that the considered model is implemented in many well-known computer programs for analysis of electronic circuits such as SPICE software [7]. Moreover, manufacturers of semiconductor devices usually provide parameter values for the mentioned model in the devices datasheets. The capacitances $\mathrm{C}_{\mathrm{bc}}$ and $\mathrm{C}_{\mathrm{be}}$ are responsible for modelling the non-linear capacitances of the base-collector and the base-emitter transistor junctions. The considered capacitances are described as follows [7]:

$$
\begin{gathered}
\mathrm{C}_{\mathrm{bc}}=\mathrm{C}_{\mathrm{tbc}}+\text { area } \cdot X C J C \cdot \mathrm{C}_{\mathrm{jbc}} \\
\mathrm{C}_{\mathrm{be}}=\mathrm{C}_{\mathrm{tbe}}+\text { area. }
\end{gathered}
$$

A detailed description of the analytical dependencies of the Gummel-Poon model, is available for example in work [7].

\section{Results of the measurements and calculations}

The paper presents the results of $\mathrm{C}-\mathrm{V}$ characteristics measurements of the arbitrarily chosen transistors: $\mathrm{SiC}$ BJT (BT1206AC) and SJT (2N7635-GA). The measurements were performed using the Keithley 4200-SCS programmable system [8] in a wide range of an ambient temperature. In the case of the SiC BJT, a set of parameter values, obtained during the estimation procedure $[9,10]$, was used in the calculations while in the case of the SJT, the calculations were performed using a set of parameter values, taken from the device datasheet [4]. Figure 1 depicts the $\mathrm{C}_{\mathrm{bc}}\left(\mathrm{v}_{\mathrm{BC}}\right)$ characteristics of the $\mathrm{SiC} \mathrm{BJT}$ where a filled points represent the results of an author's measurements, an unfilled points represent the results of measurements included in research paper [5] and a solid lines represent the results of calculations using Gummel-Poon model.

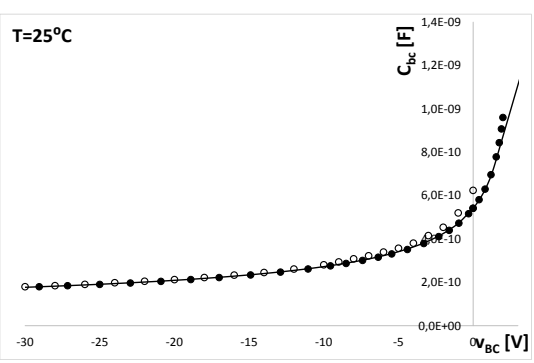

Fig.1. $\mathrm{C}_{\mathrm{bc}}\left(\mathrm{v}_{\mathrm{BC}}\right)$ characteristics of the BT1206-AC transistor at the ambient temperature equal to $25^{\circ} \mathrm{C}$.

As seen (Fig. 1), both the qualitative and quantitative agreement of the calculation results and measurements, 
in the $v_{B C}$ voltage range below $1.8 \mathrm{~V}$, was obtained, which proves the high accuracy of the Gummel-Poon model in this operation range. Figure 2 presents the temperature impact on the $\mathrm{C}_{\mathrm{bc}}\left(\mathrm{v}_{\mathrm{BC}}\right)$ characteristics. It turns out that in case of the $\mathrm{SiC} \mathrm{BJT}$, the influence of an ambient temperature on the considered $\mathrm{C}-\mathrm{V}$ characteristic is barely perceptible for the bias in the reverse direction.

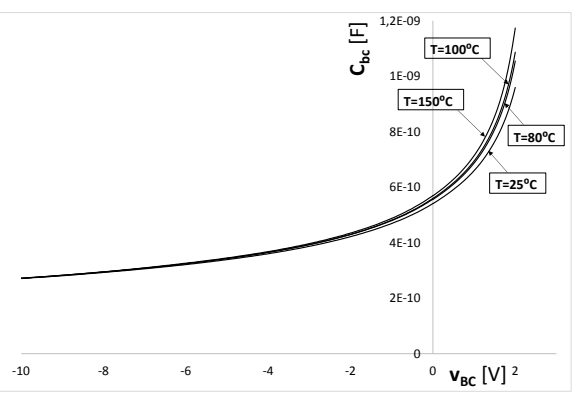

Fig.2. $\mathrm{C}_{\mathrm{bc}}\left(\mathrm{v}_{\mathrm{BC}}\right)$ characteristics of the BT1206-AC transistor in a range of the ambient temperature from $25^{\circ} \mathrm{C}$ to $100^{\circ} \mathrm{C}$.

Figure 3 shows the $\mathrm{C}_{\mathrm{iss}}\left(\mathrm{v}_{\mathrm{SD}}\right)$ and $\mathrm{C}_{\mathrm{rss}}\left(\mathrm{v}_{\mathrm{SD}}\right)$ characteristics of the considered SJT transistor at a fixed value of the base-emitter voltage equal to $0 \mathrm{~V}$. A filled points represent the results of an author's measurements, an unfilled points represent the results of measurements taken from device datasheet [4] and solid lines represent the results of calculations using Gummel-Poon model. The capacitances $C_{i s s}$ and $C_{r s s}$ are described as follows [4]:

$$
\begin{gathered}
\mathrm{C}_{\mathrm{iss}}=\mathrm{C}_{\mathrm{be}}+\mathrm{C}_{\mathrm{bc}} \\
\mathrm{C}_{\mathrm{rss}}=\mathrm{C}_{\mathrm{bc}}
\end{gathered}
$$

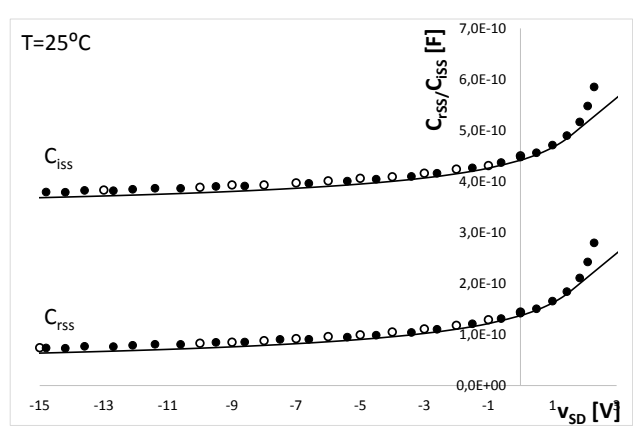

Fig.3. $C_{\text {iss }}\left(v_{\mathrm{SD}}\right)$ and $\mathrm{C}_{\mathrm{rss}}\left(\mathrm{v}_{\mathrm{SD}}\right)$ characteristics of the $2 \mathrm{~N} 7635-\mathrm{GA}$ transistor at the ambient temperature equal to $25^{\circ} \mathrm{C}$.

In the case of presented $\mathrm{C}_{\mathrm{iss}} / \mathrm{C}_{\mathrm{rss}}\left(\mathrm{v}_{\mathrm{SD}}\right)$ characteristics, a very good agreement between the results of measurements and calculations is observed in the range of $v_{S D}$ voltage below 1.6 V. It confirms that the GummelPoon model can be also successfully used for modelling the $\mathrm{C}-\mathrm{V}$ characteristics of SJTs. The slight temperature effect is visible on considered $\mathrm{C}_{\mathrm{iss}} / \mathrm{C}_{\mathrm{rss}}\left(\mathrm{v}_{\mathrm{SD}}\right)$ characteristics presented on Figure 4. For example, with the increase of the ambient temperature by $150^{\circ} \mathrm{C}$, a value of the $\mathrm{C}_{\text {rss }}$ capacitance increases for only about 20 $\mathrm{pF}$ for the base-collector junction biased in reverse direction and for about $50 \mathrm{pF}$ for the polarity in the direction of conduction.

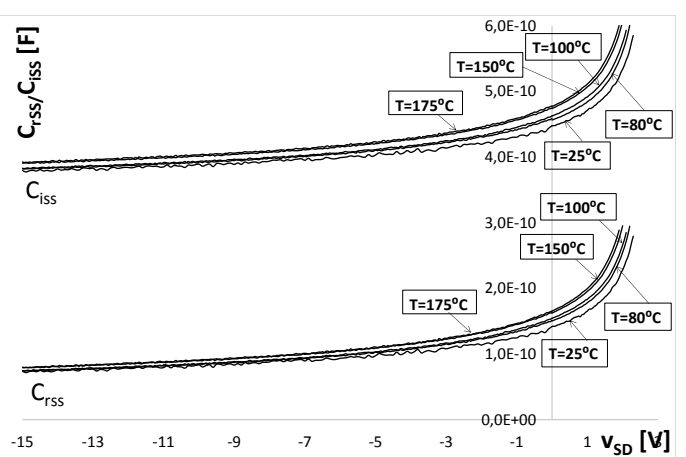

Fig.4. $C_{\text {iss }}\left(v_{\mathrm{SD}}\right)$ and $\mathrm{C}_{\mathrm{rss}}\left(\mathrm{v}_{\mathrm{SD}}\right)$ characteristics of the $2 \mathrm{~N} 7635-\mathrm{GA}$ transistor in a range of the ambient temperature from $25^{\circ} \mathrm{C}$ to $175^{\circ} \mathrm{C}$

\section{Summary}

The presented results of an experimental verification of the Gummel-Poon model show a very good agreement between the results of the measurements and calculations of $\mathrm{C}-\mathrm{V}$ characteristics, which means that the considered model can be successfully used to model these characteristics for both considered classes of transistors. In addition, the ambient temperature has a small impact on capacitance-voltage characteristics of the SiC BJT and SJT. Moreover, the measured capacitances between the base and emitter and between the base and collector of the SJT junctions have a several times lower values in comparison with the values of considered $\mathrm{SiC}$ BJT capacitances which means that the SJT transistors can potentially be used in systems operating at higher signal frequencies.

\section{References}

[1] K. Bargieł, J. Zarębski and D. Bisewski, SPICEaided modelling of high-voltage silicon carbide JFETS, 39th International Microelectronics and Packaging, (2015)

[2] K. Bargieł, D. Bisewski, Modelling of silicon carbide JFET in SPICE, 41st International Microelectronics and Packaging Poland, (2017)

[3] http://www.dacpol.eu

[4] http://www.genesicsemi.com

[5] Y. Huang, S. Cheng, W. Zhou, K. Sheng,

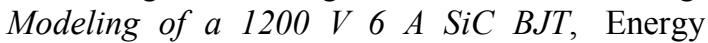
Conversion Congress and Exposition, (2013)

[6] J. Patrzyk, Modelowanie tranzystorów mocy, SJ GMU 95, 168-176 (2016)

[7] PSPICE A/D Reference Guide Version 15.7

[8] http://tespol.com.pl

[9] D. Bisewski, Estimation of parameters of GaAs and SiC MESFETs using genetic algorithm, $45^{\text {th }}$ International Conference on Microelectronics, Devices and Materials, 81-84 (2009)

[10] D. Bisewski, Parameters estimation of SPICE models for silicon carbide devices, $21^{\text {st }}$ European Microelectronics and Packaging Conference (EMPC) \& Exhibition, 1-4 (2017) 